\title{
INTEGRATION OF SUSTAINABILITY INTO EARLY DESIGN THROUGH WORKING KNOWLEDGE MODEL AND VISUAL TOOLS
}

\author{
Srikanth Devanathan, Pranav Koushik, Fu Zhao, Karthik Ramani \\ School of Mechanical Engineering, \\ Purdue University \\ West Lafayette, IN, USA
}

\begin{abstract}
The issue of environmental sustainability, which is unprecedented in both magnitude and complexity, presents one of the biggest challenges faced by modern society. Engineers, including mechanical engineers, can make significant contribution to the development of solutions to this problem by designing products and processes that are more environmentally sustainable. It is critical that engineers take a paradigm shift of product design i.e. from cost and performance centered to balance of economic, environmental, and societal consideration. Although there have been quite a few design for environment (DfE, or ecodesign) tools developed, so far these tools have only achieved limited industrial penetration: they are either too qualitative/subjective to be used by designers with limited experiences, or too quantitative, costly and time consuming and thus cannot be used during the design process specially during the early design stage. This paper develops a novel, semi-quantitative ecodesign tool that targets specially on early design process. The new tool is a combination of environmental life cycle assessment, working knowledge model, and visual tools such as QFD, functional-component matrix, and Pugh chart. Redesign of staplers is selected as a case study to demonstrate the use of the proposed tool. Efforts are on going to confirm that the new design generated using this new tool does have improved environmental performance.
\end{abstract}

\section{INTRODUCTION}

The issue of environmental sustainability, which is unprecedented in both magnitude and complexity, presents one of the biggest challenges faced by modern society (NAE, 2008). This is even more challenging if population growth and increase in the quality of life are taken into consideration (Chertow, 2001). Engineers, including mechanical engineers, can make significant contribution in developing solutions to address this issue by designing products and processes that satisfy the needs of the society while minimizing the associated environmental consequences. Therefore, it is critical that engineers adopt a design paradigm shift from cost and performance centered to a balance of economic, environmental, and societal consideration (Mihelcic et al. 2008; Papas et al., 2008). However, designing products that are environmentally friendly is by no means an easy task due to the fact that, engineered products like living organisms interact with the environment through energy and material flows at every stage of its life cycle, i.e. from raw materials extraction and acquisition, manufacturing, transportation and distribution, use and maintenance, reuse and recycle, and all the way to disposal and waste management (Curran, 2006). This life cycle perspective further complicates product design when environmental sustainability is integrated into design consideration.

As pointed out by Pugh, "the wrong choice of concept in a given design situation can rarely, if ever, be recouped by brilliant detail design" (Pugh, 1991). This is also expected to be the case for environmentally friendly design. Till now design methods such as Quality Function Deployment (QFD), functional component analysis, and Pugh chart have gained prominence in the product design community as means to develop better products. Unfortunately the decisions typically rely on experience, intuition, or at best, on a few simplified calculations (Iqbal et al., 2008). As a result, the choices made or design concepts selected are viewed with skepticism and are not free from biased and unsupported choices. The case is even worse when environmental performance is considered as a design factor since only very limited experience and knowledge have been accumulated and usually a "life cycle" perspective is missing (UNEP, 2005; Fargnoli et al., 2006).

Product design and development relating to improved environmental performance has many expressions including design for environment, ecological design, environmental design, environmentally conscious design, environmentally 
responsible design, socially responsible design, sustainable product design, sustainable product development, green design and life cycle design (Lee et al., 2005). Ecodesign is used throughout this paper to represent all these efforts. During the past decade, there have been quite a few ecodesign tools developed. However, these tools are usually at two extremes: they are either too qualitative and subjective, thus cannot offer concrete solutions but require the designer to have extensive experiences and expertise in order to make a sound decision; or, they are too complicated and quantitative thus cannot be used during design process especially during early design when product specifications are still under development (Sakao, 2007; Boks, 2006). Moreover, usually these tools are stand-alone and not well integrated into traditional design tools. As a result, these tools only achieve very limited penetration to industry (Cooper et al., 2006; Lofthouse, 2006).

In the authors' previous work, a working knowledge model that collates information from commonly used visual tools to support iterations in conceptual design has been developed to bring more objectivity into early design process. In this paper, a novel ecodesign method will be developed which is a combination of life cycle assessment and the working knowledge model. The new method will be demonstrated using stapler re-design as a case study.

\section{LITERATURE REVIEW}

During the past ten years numerous ecodesign tools have been proposed and developed. In fact, ISO-TR 14062 (ISO, 2002) suggests the use of some 30 various tools. These tools can be generally classified into three categories: i.e. tools based on checklists, tools based on LCA (Life Cycle Assessment), and tools based on QFD (Fargonoli et al., 2006). In the following paragraphs a brief review on these tools is provided.

Tools based on LCA. Life Cycle Assessment (LCA) method was developed to identify and avoid potential shifting of environmental consequences from one life cycle stage to another, from one geographic area to another, and from one environmental medium to another. That is, LCA takes a holistic approach and therefore presents a more accurate picture of the true environmental trade-offs of engineered products. The method was standardized by ISO in 1997 and updated in 2006 (ISO, 2006). So far LCA is the most objective tool available for generating environmental profile of a product. However, LCA requires detailed product design information which makes it unsuitable for use in early design process when a detailed specification is not available yet (Sakao, 2007). This is especially true for new product design since even information from reference products (previous generation or competitors) is not available. Also, LCA could be very costly and time consuming so only large companies can afford doing it. There have been some efforts in addressing these issues by developing simplified or streamline LCA for screening purpose. But again, these methods tend to ignore environmental impacts from certain life cycle stages, certain material/energy flows, or certain impact categories (Todd et al., 1999; Koffler et al., 2008). To what level the fidelity can be maintained remains largely unaddressed. Another serious obstacle associated with applying LCA based tools to early design lies on the fact that inherently LCA is not design-oriented i.e. it is designed to analyze certain structure and components, not environmental cost associated with functions required by customers as well as technologies used to achieve those functions. Figure 1. shows how LCA is traditionally used in product development.

Tools based on checklists. These qualitative tools are the easiest to use and are among the tools prevailing most in industry, especially small and medium size companies (Luttropp et al., 2006). A common feature of these tools is the checklist, which is a set of items used for assessing a product from environmental perspective over its entire life cycle. Those items include, for example, "is less energy consumed during the use phase of the product than the existing ones?" or "are less toxic materials used in the product?" (Lee at al., 2005). These tools are developed particularly for the early stages of the product development process. Compared with LCA based tools, these tools are much more subjective. The proper use of the tools requires extensive experience and knowledge. Even with that, it remains a challenge when tradeoffs exist between different life cycle stages or different environment impacts categories. Moreover, these tools can rarely offer concrete solutions.

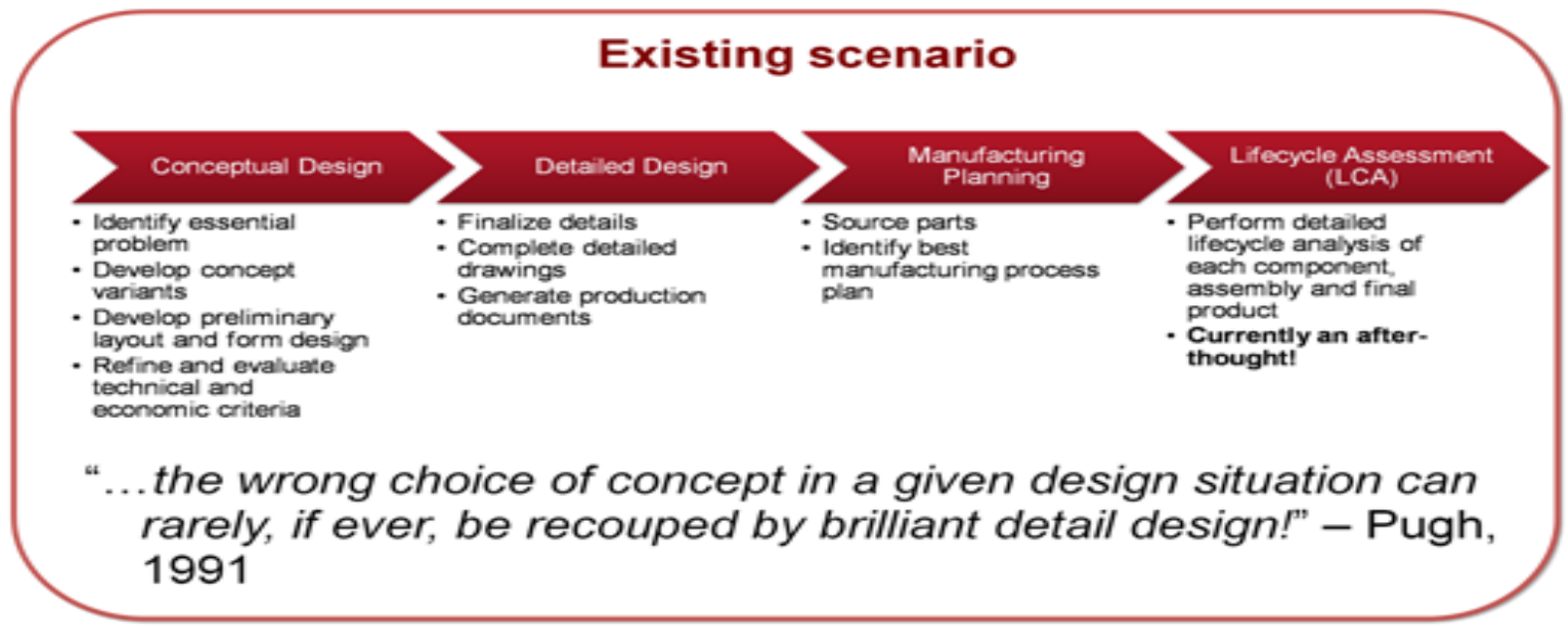

FIGURE 1.IN THE EXISTING SCENARIO, THE ENVIRONMENTAL IMPACT IS ESTIMATED AFTER THE PRODUCT HAS BEEN DESIGNED: THERE ARE NO MEANS FOR ESTIMATING THE IMPACT AT THE CONCEPTUAL DESIGN STAGE. 
Tools based on QFD. The objective of a traditional QFD is to convert customers' needs into engineering characteristics and at the same time improve the quality level of the product. By introducing environmental impacts of the product itself and over its life cycle into QFDs as new customer needs, a set of ecodesign tools have been developed. These include Quality Function Deployment for the Environment, Green Quality Function Deployment, and House of Ecology (Masui et al., 2003; Sakao, 2007). In general, application of these tools starts from collecting both customer needs and environmental needs, and developing correlations between these needs and quality characteristics. A functional analysis is then performed to identify how quality characteristics are correlated with engineering characteristics (including structure or components) and hot spots from both environmental as well as traditional qualities point of views. It can be observed that QFD based tools are significantly different from LCA based tools since the focus here is on the product specification development stage. One serious drawback of these QFD based tools (similar to traditional QFD) is that the development of correlations between environmental needs and quality \& engineering characteristics is totally on designers, and usually the correlations developed are based on knowledge from traditional environmental engineering discipline without the consideration of life cycle.

In summary, QFD based tools are more suitable for the early product development phase when specifications are being established and concepts are being generated. However, without support from LCA, QFD based tools may lead to biased identification of design targets. So naturally one may argue a combined QFD/LCA tool may be more promising. Actually this has been the focus of recent efforts on developing ecodesign tools (Sakao, 2007). But still, there are critical missing links in the above stated approach, which leaves the inherent drawback of QFD left unaddressed, i.e., although LCA results are used to develop voices of environment and weighting, they are not used to develop correlations between environmental needs and quality \& engineering characteristics.

In the authors' previous work (Devanathan et al., 2009), a methodology suitable for early design has been developed which supports manual reasoning by mapping the elements of the visual tools to the working knowledge model (WKM) (see Figures $2 \& 3$ ). Another key aspect of the WKM is the ability to handle multiple descriptions and alternatives of the DesignModel, encountered in the initial stages of the design process. The supported visual tools include: function-means trees, function flow diagrams, function-component matrices, SysML Requirements diagram, and the House of Quality. WKM serves as a repository for all the information encountered in early design namely, (1) the structure and behavior representations of competing products, (2) the

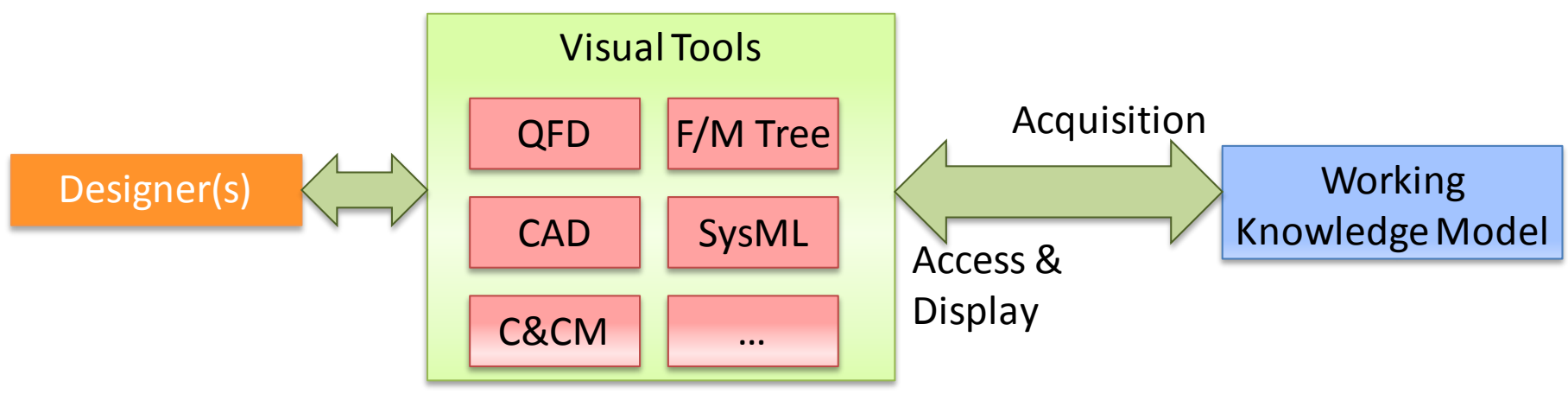

FIGURE 2. WORKING KNOWLEDGE MODEL (WKM) PROVIDES A FRAMEWORK FOR STRUCTURING AND ACCESSING INFORMATION USED IN EARLY DESIGN THROUGH MEANS OF VISUAL TOOLS

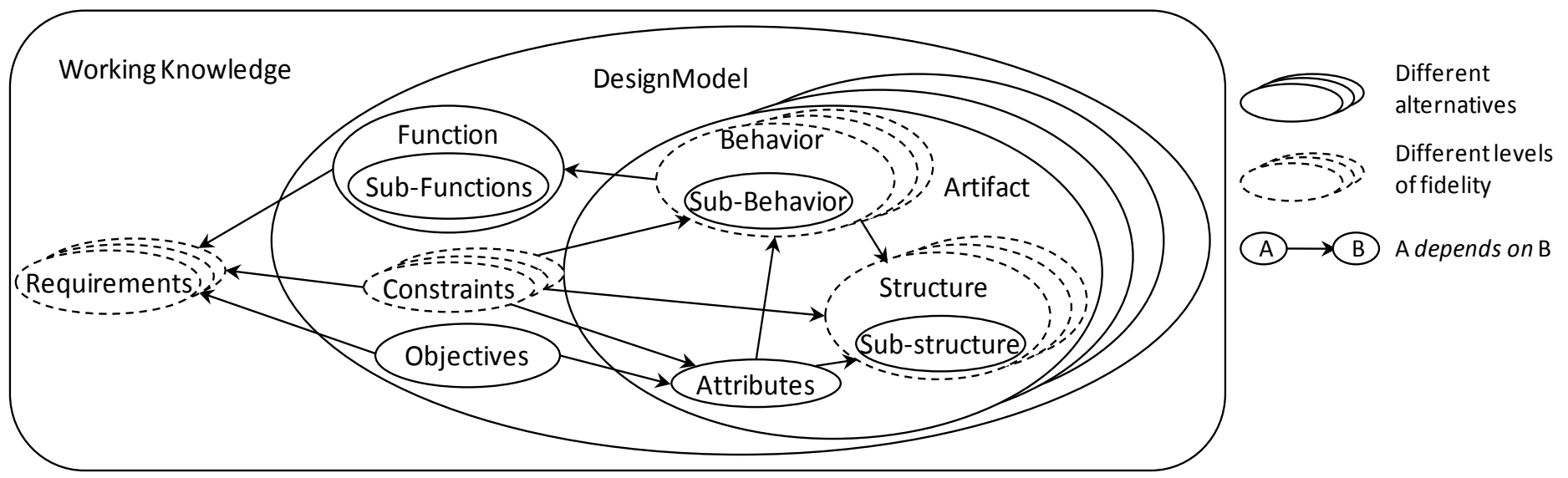

FIGURE 3. PRODUCT INFORMATION ENTITIES THAT ARE CONSIDERED WITHIN THE WORKING KNOWLEDGE MODEL 
alternative design concepts, and (3) the various refinements of the function, structure and behavior descriptions of the current design solution. This methodology was applied successfully to capture a significant portion of the working knowledge during the design of a Humanoid Robot in collaboration with the Institute for Product Development IPEK, at University of Karlsruhe, Germany. Figure 4 illustrates how the elements of the WKM can be used to describe the content of specific visual tools. One of the salient aspects of being able to model the information content of visual tools is that, the visual tools can be chained to maintain consistency among these tools during the several iterations that occur in early design and also eliminate the need to manually enter the same information several times for different tools. Evidently, the working knowledge model provides a way to address the missing link in the QFD based ecodesign approach.

\section{METHOD DEVELOPMENT}

The novel ecodesign methodology proposed here is a seamless integration of life cycle assessment and working knowledge model based visual tools. To make approach clear, we use design of staplers as a didactic example (See Figure 5 for the overall approach). Most of these staplers available in the market today consist of a magazine to hold staples, an extruder to push a staple through a pile of papers, a bottom plate to crimp the ends of the staple pin, and a housing to hold all the parts together. These staplers are made of different material such as plastics and metal. We would first like to estimate the contribution of each function performed by the stapler in addressing the user requirements. In this study, three representative staplers on market are selected as benchmarks i.e. an all metal one, a plastic one, and a compact one. It is also assumed that all staplers have a service life of five years and staple 5000 documents during life time. It can be observed that (1) any new design is a novel combination of existing concepts, and (2) product tear-down and benchmarking are an essential part of any design process (Otto and Wood, 1999). During the tear-down, designers identify the structure and functions of competing products. Table 1 lists the bill of materials for one of the benchmark staplers. Eco-analysis such as LCA can be performed for a given product structure and scores can be provided for the environmental impacts. Here the environmental impacts considered are limited to global warming in terms of carbon dioxide equivalent but other impact categories can be also considered if desired. Figure 6 shows the LCA process tree and global warming potential contribution based on product tear-down and bill of materials as listed in Table 1. An interesting fact observed is that for staplers the use phase dominates the life cycle environmental impacts. For the stapler analyzed, a jam rate of $20 \%$ is assumed. This suggests that a jam-free stapler may have better environmental performance if this is achieved without significantly increasing the environmental impacts associated with the stapler itself. Moreover, LCA results of other staplers suggest that the stapler made of mainly plastics is superior when compared with the one made of metal from environmental perspective.

Now, the challenge lies on how to interpolate the impact of existing products so they can be used towards the new design. This is indeed possible because, (1) products are designed to perform certain function, (2) the products achieve the functionality by means of their structure and behavior (use) (Gero, 1990), and (3) the environmental impact is computed using the structure and usage information. Therefore there exists a theoretical pathway to connect functional information to the environmental impact data through the structure of existing product. It is therefore, possible to estimate the environmental impact of each function, albeit for existing products. Extrapolating the impact for the functions of the current design provides a means to (1) rank the functions in terms of their environmental impact, and (2) estimate a baseline impact that the new design should improve.

TABLE 1. BILL OF MATERIALS FOR A STAPLER

\begin{tabular}{cclr}
\hline Item Name & Qty. Material & $\begin{array}{l}\text { Predominant } \\
\text { process }\end{array}$ & Weight $\mathbf{( g )}$ \\
\hline 1 Top housing & 1 Plastic & Injection molding & 20.5 \\
2 Bottom housing & 1 Steel & Stamping & 30.1 \\
3 Magazine indexer & 1 Copper & Blanking & 1.3 \\
4 Magazine guide & 1 Steel & Stamping & 8.1 \\
5 Magazine spring & 1 Spring Stt Extrusion & 1.2 \\
6 Impact plate & 1 Steel & Blanking & 3.6 \\
7 Extruder & 1 Steel & Blanking & 1.4 \\
\hline
\end{tabular}

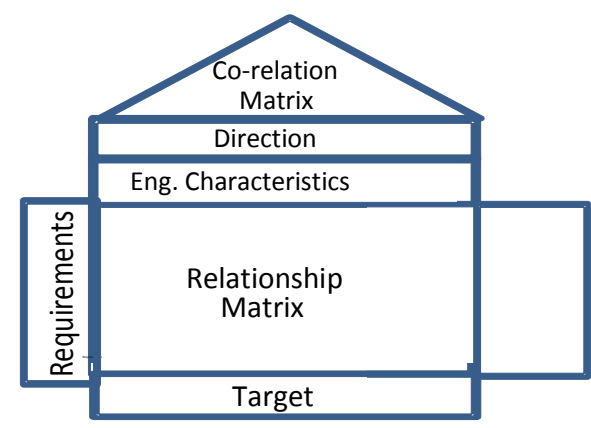

(a) House of Quality

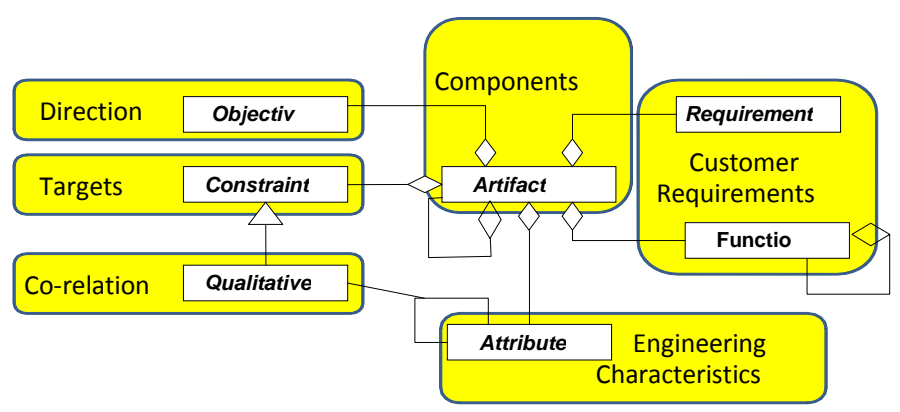

(b) Elements of the Working Knowledge Model

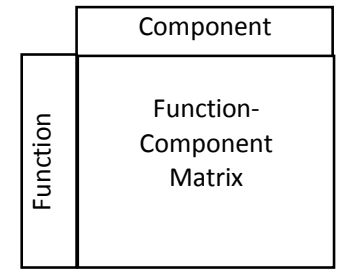

(c) Function-Component Matrix

FIGURE 4. DESCRIPTION OF THE HOUSE OF QUALITY AND FUNCTION-COMPONENT MATRIX USING WKM ELEMENTS (DEVANATHAN ET AL., 2009) 


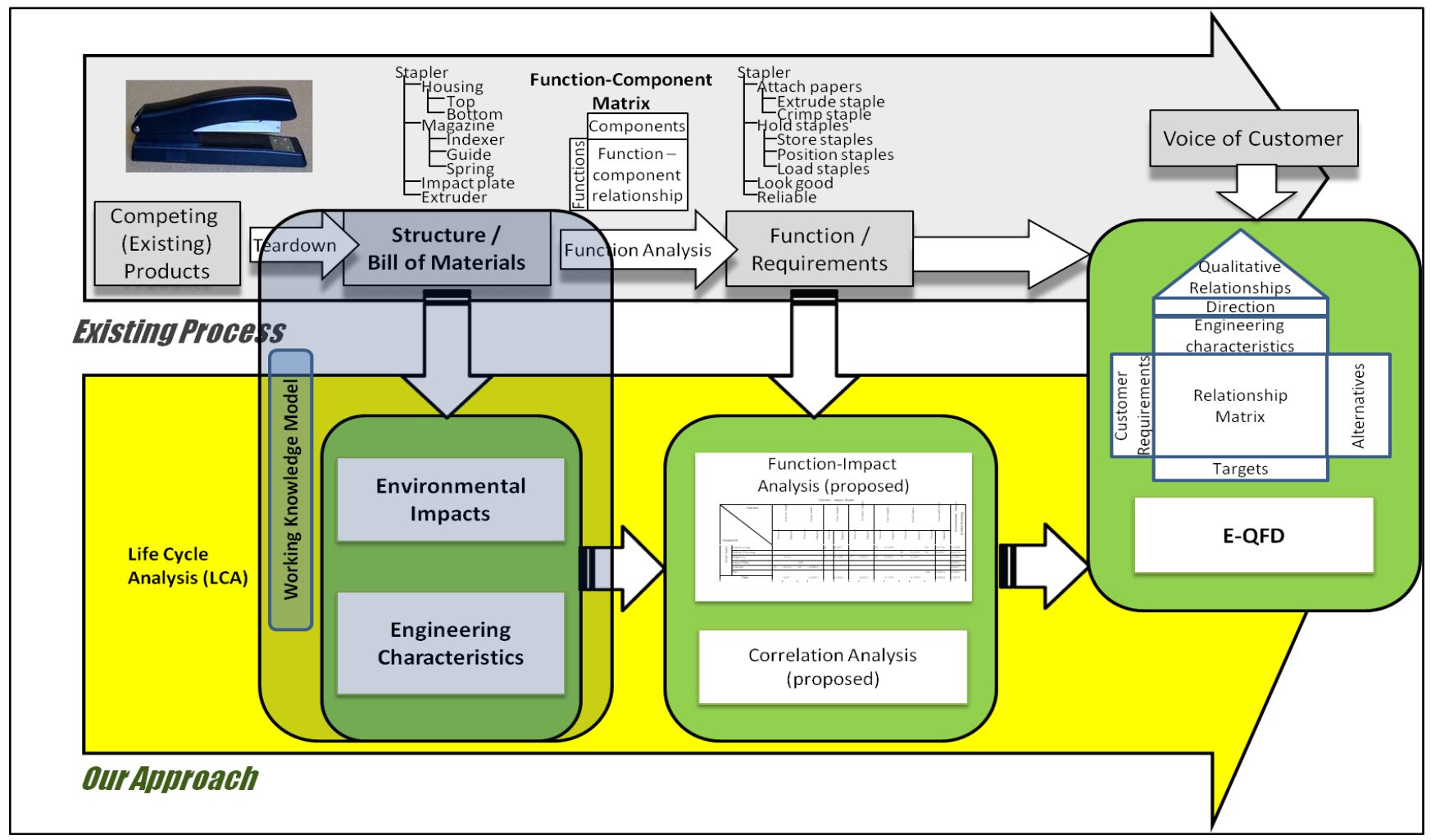

FIGURE 5. OVERVIEW OF THE APPROACH THAT INTEGRATES LIFE CYCLE ASSESSMENT AND VISUAL TOOLS FOR THE STAPLER EXAMPLE

Here a new visual tool called the Function-Impact Matrix that uses information from Function-Component matrix to distribute the environmental impact scores across the functions performed by the product (stapler) is proposed. An example of the function-impact matrix is shown in Figure 6. Similar analysis can be performed for all the competing staplers and an average impact of particular function can be obtained. Although the actual impact of the particular function for a new stapler will differ from this value, it nevertheless provides a baseline needed for decision making. The main aspect of the function-impact matrix is to identify which functions are important and which functions need to be re-examined to obtain a better design. The function-impact matrix is drawn for all the competing staplers and the average impact of each function is depicted in Figure 8. From this figure, it is clear the function "transmit force" accounts for $40 \%$ of the total impact of the stapler. It should be noted that the impact of any new function that is not performed by existing competing product

\begin{tabular}{|c|c|c|c|c|c|c|c|c|c|c|c|c|c|c|c|}
\hline \multirow[b]{2}{*}{ Component } & \multicolumn{2}{|r|}{ 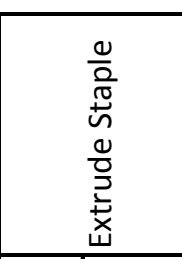 } & \multicolumn{2}{|r|}{ 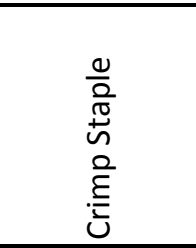 } & \multicolumn{2}{|r|}{ 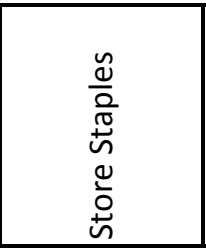 } & \multicolumn{2}{|r|}{ 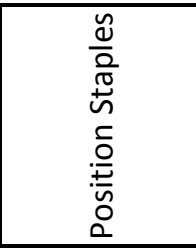 } & \multicolumn{2}{|r|}{$\begin{array}{l}\frac{\tilde{\omega}}{0} \\
\frac{2}{\pi} \\
\tilde{\omega} \\
0 \\
\frac{\pi}{0} \\
0\end{array}$} & \multicolumn{2}{|r|}{$\begin{array}{l}\frac{n}{0} \\
\frac{0}{0} \\
\frac{0}{0} \\
\text { 음 } \\
\text { I }\end{array}$} & \multicolumn{2}{|r|}{ 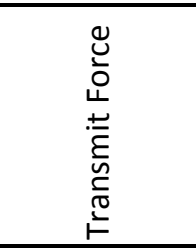 } & \multirow{2}{*}{ 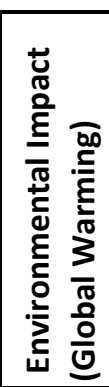 } \\
\hline & 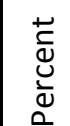 & $\begin{array}{l}\overleftarrow{U} \\
\tilde{\pi} \\
\underline{\underline{E}}\end{array}$ & 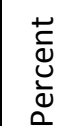 & 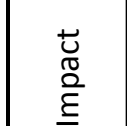 & 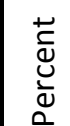 & $\begin{array}{l}\stackrel{+}{0} \\
\mathbb{\pi} \\
\stackrel{\Omega}{E}\end{array}$ & 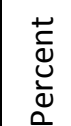 & 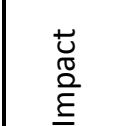 & 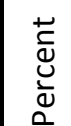 & 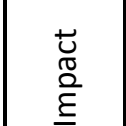 & 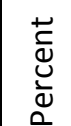 & 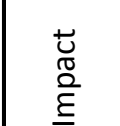 & 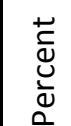 & 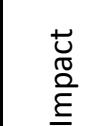 & \\
\hline Top Housing & & & & & 30 & 0.223 & & & 20 & 0.1486 & & & 50 & 0.3716 & 0.7432 \\
\hline Bottom Housing & & & & & & & & & & & 30 & 0.1372 & 50 & 0.2287 & 0.4574 \\
\hline Magazine & 5 & 0.011 & & & 65 & 0.1435 & 10 & 0.0221 & 10 & 0.0221 & 10 & 0.0221 & & & 0.2207 \\
\hline Impact Plate & & & 100 & & & & & & & & & & & & 0.0531 \\
\hline Extruder & 70 & 0.019 & 30 & 0.0081 & & & & & & & & & & & 0.0271 \\
\hline Pins & & & & & & & & & & & & & 100 & 0.0561 & 0.0561 \\
\hline Total & & 0.03 & & 0.0081 & & 0.3664 & & 0.0221 & & 0.1707 & & 0.1593 & & 0.6564 & 1.5576 \\
\hline
\end{tabular}

FIGURE 6. FUNCTION-IMPACT MATRIX FOR ESTIMATING THE IMPACT OF INDIVIDUAL FUNCTIONS THROUGH MEANS OF THE STRUCTURE INFORMATION 


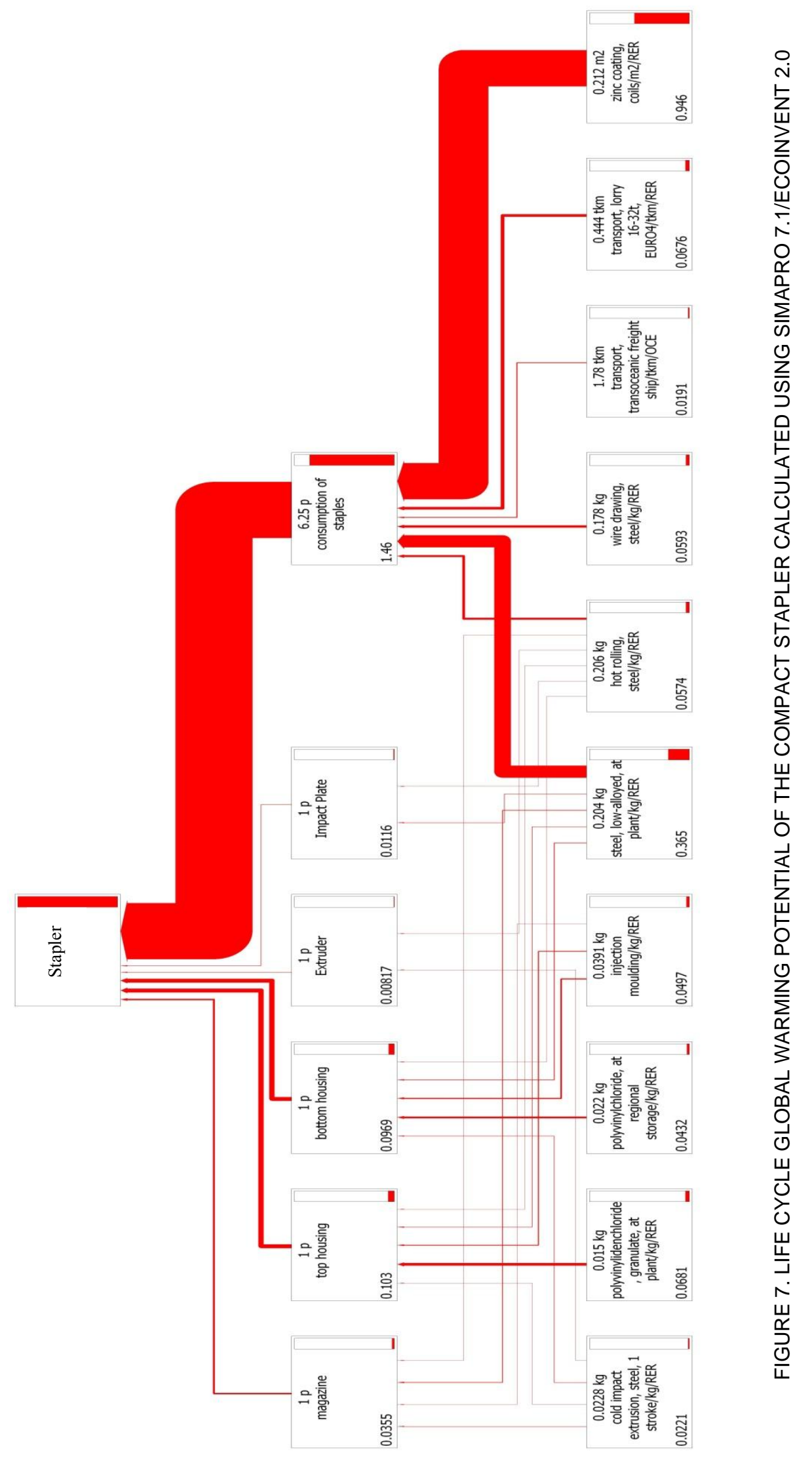


cannot be estimated using this approach directly. However, if it is known that the new function is actually "borrowed" from another type of products (this is true in most innovations), the working knowledge model can be expanded by adding data obtained from LCA of those products.

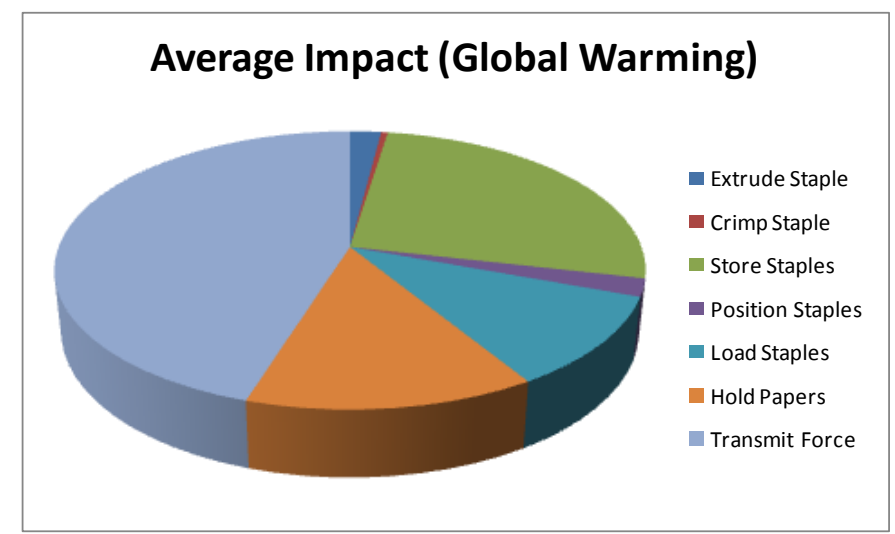

FIGURE 8. AVERAGE CONTRIBUTION OF EACH FUNCTION TO THE OVERALL IMPACT OF THE STAPLER

Based on LCA results, an updated QFD (also known as EQFD) that includes both the voice of customer and the voice of environment can be developed, as shown in Figure 9. In this E-QFD, it can be observed that the environmental impact arising from the inability to staple papers in the first attempt is significant and needs careful consideration while conducting re-design and development of jam-free staplers.

The function-impact matrix can also be extended for concept selection, since new concepts that are generated involve working principles that are already embodied in other (possibly very different) products. Continuing our stapler example, a new "Power-ease" stapler stores the energy applied by the user and then releases it as an impulse to "shoot" the staple into the papers. Here, many working principles for the functions of 'store energy' and 'release energy' can be developed. As a possible working principle, the applied force can be used to move an electrical device that converts the mechanical energy into electrical energy and use a liner motor to extrude the staple. To estimate the environmental impact of this concept, one can look at other products that convert mechanical energy into electrical energy and back. By suitably choosing the structural boundary of the existing product, and after appropriate scaling, we can use the function-impact matrix to estimate the impact of the new function. For the new "Power-ease" stapler, a leverage-spring mechanism could be added to store the energy and then "shoot" the staple into the papers. This new design is expected to significantly reduce jam while only introducing minimal extra parts (potentially increase environmental impacts only slightly). To confirm the environmental benefits of the new, plastic Power-ease stapler, a new round of LCA is needed. Efforts are on-going to complete the detailed design of the new stapler in order to provide required specifications for the LCA.

To summarize, in order to use the methodology for product development, LCA will first be conducted on market leading models of several different types of consumer products (e.g. staplers, coffee makers, BBQ grills) using information collected from product tear-down and bill of materials. The environmental impacts will then be integrated into the working knowledge model to support conceptual design and concept selection. If desired, another round of LCA will be conducted on the detailed designs developed based on all major concepts to check whether or not the ranking of concepts against environmental performance is consistent with that based on LCA.

\section{CONCLUSIONS}

In this paper, a novel ecodesign method is proposed which is an extension of the authors' previous work on the development of a working knowledge model for supporting early design through visual tools. The proposed method starts with life cycle assessment of benchmark products and the environmental impacts are integrated into the working knowledge model. A new visual tool called the FunctionImpact Matrix that uses information from FunctionComponent matrix to distribute the environmental impact scores across the functions performed by the product is then developed. Combined with traditional function-component matrix, the function-impact matrix is used to generate an environmental QFD. After concept generation, the new function-impact matrix is also be used for concept selection. The novel approach is demonstrated in this paper through the redesign of a stapler for smaller carbon footprint. A plastic stapler, which is jam-free by adapting a leverage-spring mechanism that stores energy then release it in an impulse to shoot staples into papers, is suggested as a more environmentally friendly alternative. Efforts are on-going to complete the detailed design in order to confirm its superior environmental performance through LCA.

\section{ACKNOWLEDGEMENT}

We thank the Division of Environmental and Ecological Engineering at Purdue University for providing financial support in the form of a curriculum development grant, which makes it possible to purchase SimaPro 7.1 and Ecoinvent 2.0 software packages used in this study. Besides, Devanathan acknowledges the support provided by the Purdue Product Life Cycle Management Center and the Center for Advance Manufacturing.

\section{REFERENCES}

[1] Boks, C., "The Soft Side of Ecodesign", Journal of Cleaner Production, Vol.14, 2006, pp.1346-1356.

[2] Chen, C.F., "The Instructional Models and Guidelines for Developing a Curriculum in Eco-design", Proceedings Second International Symposium on Environmentally Conscious Design and Inverse Manufacturing, 2001, pp.625-630.

[3] Chertow, M.R., "The IPAT Equation and Its Variants: Changing Views of Technology and Environmental Impact", Journal of Industrial Ecology, Vol.4, 2001, pp.13-29. 

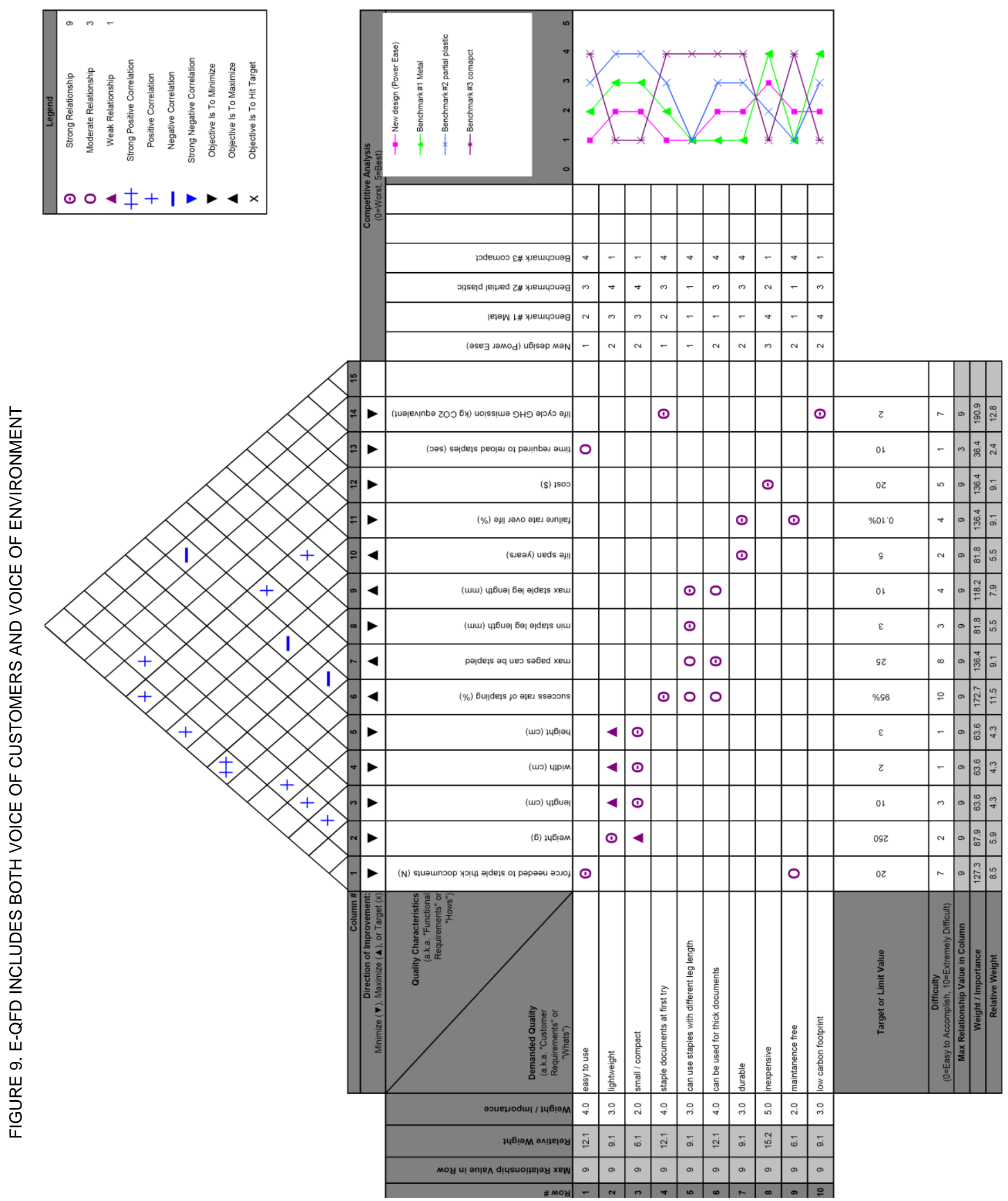
[4] Cooper, J.S., Fava, J.A.," Life-Cycle Assessment Practitioner Survey: Summary of Results", Journal of Industrial Ecology, Vol.10, 2006, pp.12-14.

[5] Curran, M.A., "Life Cycle Assessment: Principles And Practice", EPA/600/R-06/060, 2006.

[6] Devanathan, S., Sauter, C., Albers, A., Ramani, K., "A working knowledge model for supporting early design through visual tools", International Conference on Engineering Design (ICED), 2009, Stanford, CA, USA (accepted).

[7] Fargnoli, M., Kimura, F., "Sustainable Design of Modern Industrial Products", Proceedings of $13^{\text {th }}$ CIRP International Conference on Life Cycle Engineering, 2006, pp.189-194.

[8] Gero J.S., "Design Prototypes: A Knowledge Representation Schema for Design", AI Magazine, Vol. 11(4), 1990, pp. 26-36.

[9] Iqbal, L., Crossley, W., Weisshaar, T. and Sullivan, J., "Higher Level Design Methods Applied to the Conceptual Design of an MALE UAV," AIAA-2008-5908, 12th AIAA/ISSMO Multidisciplinary Analysis and Optimization Conference, Victoria, BC, Sep. 10-12, 2008.

[10] ISO TR 14062: Environmental Management - Integrating Environmental Aspects into Product Design and Development, 2002.

[11]ISO 14040, Environmental Management -- Life Cycle Assessment -- Principles and Framework, 2006.

[12] ISO 14044, Environmental Management -- Life Cycle Assessment -- Requirements and Guidelines, 2006.

[13] Koffler, C., Krinke, S., Schebek, L., Buchgeister, J., "Volkswagen slimLCI: A Procedure for Streamlined Inventory Modeling within Life Cycle Assessment of Vehicles", International Journal of Vehicle Design, Vol.46, 2008, pp.172-188.

[14] Lee, K.M., Park, P.J., "EcoDesign: Best Practice of ISO14062”, Eco-product Research Institute(ERI), Ajou University, Korea, 2005.

[15] Lofthouse, v., "Ecodesign Tools for Designer: Defining the Requirements", Journal of Cleaner Production, Vol.14, 2006, pp.1386-1395.

[16] Luttropp, C., Lagerstedt, J., "EcoDesign and the Ten Golden Rules: Generic Advice for Merging Environmental Aspects into Product Development", Hournal of Cleaner Production, Vol.14, 2006, pp.13961408.

[17] Masui, K., Sakao, T., Kobayashi, M., Inaba, A., "Applying Quality Function Deployment to Environmentally Consious Design", International Journal of Quality and Reliability Management, Vol.20, 2003, pp.90-106.

[18] Matthews, H.S., Environmental Life Cycle Assessment, Course Materials, 2006, http://www.ce.cmu.edu/ hsm/lca2006/, accessed March 1 st, 2009.

[19] Mihelcic, J.R., Paterson, K.G., Phillips, L.D., Zhang, Q., Watkins, D.W., Barkdoll, B.D., Fuchs, V.J., Fry, L.M., Hokanson, D.R., "Educating Engineers in the Sustainable Futures Model with a Global Perspective", Civil
Engineering and Environmental Systems, Vol. 25, 2008 , pp. 255-263.

[20] National Academy of Engineering, "Grand Challenges for Engineering", 2008.

[21] Otto K.N., Wood, K.L., Product Design: Techniques in Reverse Engineering and New Product Development, Prentice Hall, 2001.

[22] Pugh, S., "Conceptual Design," in Total Design: Integrated Methods for Successful Product Engineering, Addison-Wesley, 1991, pp. 67-100.

[23] Pappas, E.C., Kander, R.G., "Sustainable engineering design at James Madison University", Proceedings Frontiers in Education Conference, 38th ASEE/IEEE Frontiers in Education Conference, 2008, pp.T4C.14T4C.15.

[24] Sakao, T., "A QFD-centred Design Methodology for Environmentally Conscious Product Design", International Journal of Production Research, Vol.45, 2007, pp.4143-4162.

[25] Todd, J.A., Curran, M.A., "Streamlined Life-Cycle Assessment: A Final Report from the SETAC North America Streamlined LCA Workgroup", Society of Environmental Toxicology and Chemistry (SETAC) and SETAC Foundation for Environmental Education, 1999.

[26] UNEP, "Life Cycle Approaches: The Road from Analysis to Practice", A UNEP/ SETAC Life Cycle Initiative Report, 2005. 
